\title{
A PARTICIPAÇÃO SOCIAL PÓS-CONSTITUIÇÃO DE 1988: 0 QUE SE TEM DISCUTIDO A RESPEITO?
}

\author{
SOCIAL PARTICIPATION AFTER BRAZIL'S 1988 CONSTITUTION: WHAT HAS BEEN DISCUSSED? \\ LA PARTICIPACIÓN SOCIAL POSCONSTITUCIÓN DE 1988: ¿QUÉ SE HA DISCUTIDO AL RESPECTO?
}

\section{Resumo}

0 presente estudo teve como objetivo analisar o que se discutiu sobre a temática participação social a partir da Constituição Federal Brasileira de 1988, bem como apontar quem são os principais autores que têm se dedicado a estudar o tema, em quais instituições, em quais áreas a participação vem sendo discutida e qual o perfil metodológico adotado nas publicações. Para isso, refletiu-se sobre as diversas denominações dadas à participação e como se deu a trajetória da agenda de pesquisa nas últimas duas décadas. Os procedimentos metodológicos adotados foram o metaestudo e a análise de conteúdo. Como conclusão, verificou-se que os estudos sobre a participação social tiveram um aumento a partir do ano de 2003 e que há uma concentração das pesquisas na área da saúde. Observou-se, também, que os principais pesquisadores os quais discutem o tema fazem parte da Universidade Federal de Viçosa. Por fim, verificou-se que existe uma pluralidade temática que perpassa o tema, o que contribui para diferentes perfis metodológicos.

Palavras-chave: Constituição Federal, metaestudo, participação social, governo, pesquisa.

Cristina Caetano de Aguiar - cristinaaguiar15@yahoo.com.br

Professora da Faculdade Dinâmica do Vale do Piranga - Ponte Nova - MG, Brasil

Fábio Simão da Cunha - fabio.cunha.sc@gmail.com

Mestre em Administração pela Universidade Federal de Viçosa - Viçosa - MG, Brasil

Submetido 02.09.2016. Aprovado 17.01.2017

DOI: http://dx.doi.org/10.12660/cgpc.v22n71.64000 


\section{Abstract}

The present study aimed to analyze what has been discussed about social participation since the enactment of Brazil's 1988 Federal Constitution, as well as to identify the main authors who have dedicated themselves to study the subject, the institutions and areas this participation has been discussed at, and the methodological profile adopted in publications. To that end, we reflected on the different denominations given to participation, as well as on the trajectory of research agenda over the last two decades. Our methodological procedures were meta-study and content analysis. We found that studies on social participation increased since 2003 and that there is a concentration of research in the health area. We also found that the main researchers discussing the subject are members of the Federal University of Viçosa. Finally, we verified that a thematic plurality pervades the subject, which contributes to different methodological profiles.

Keywords: Federal Constitution, meta-study, social participation, government, research.

\section{Resumen}

Este estudio tuvo como objetivo analizar lo que se discutió sobre el tema de la participación social a partir de la Constitución Federal de Brasil de 1988, e identificar quiénes son los principales autores que se han dedicado a estudiarlo, en qué instituciones, en qué áreas la participación está siendo discutida, y cuál es el perfil metodológico adoptado en las publicaciones. Para ello, se reflexionó sobre las diversas denominaciones dadas a la participación y cómo se desarrolló la trayectoria de la agenda de investigación en las últimas dos décadas. Los procedimientos metodológicos adoptados fueron el metaestudio y el análisis de contenido. Como conclusión, se verificó que los estudios sobre participación social han aumentado desde el año 2003 y que existe una concentración de las investigaciones en el área de la salud. También se observó que los principales investigadores que discuten el tema pertenecen a la Universidad Federal de Vicosa. Finalmente, se confirmo que hay una pluralidad temática que domina la investigación, lo que contribuye a diferentes perfiles metodológicos.

Palabras clave: Constitución Federal, metaestudio, participación social, gobierno, investigación.

\section{INTRODUÇÃO}

No Brasil, a Constituição Federal de 1988 (CF/88) representou uma resposta às demandas sociais que clamavam por uma voz ativa na gestão pública, tendo decorrido 21 anos de ditadura militar, vividos no período de 1964 a 1985.

Conhecida como "Constituição Cidadã", a CF/88 instaurou elementos democráticos na gestão das políticas públicas e propôs um novo desenho, fundamentado nos princípios da descentralização, municipalização e participação da sociedade civil na gestão das políticas públicas (Teixeira, 2007), sendo esse último o foco de análise deste metaestudo. Ela marcou, também, a institucionalização de muitos direitos sociais, tais como: à assistência social, à saúde, ao saneamento, dentre outros.
Partindo do pressuposto de que, em um Estado descentralizado, é fundamental a presença de canais efetivos de participação, foram criados vários mecanismos com o objetivo de propiciar à sociedade civil acesso ao governo e participação nas tomadas de decisões sobre diferentes problemas públicos. $\mathrm{O}$ surgimento de novos canais de comunicação entre a sociedade civil e o Estado passou a constituir um instrumento essencial da gestão pública, evidenciando aspectos da dinâmica política democrática (Martins, 2010).

No entanto, nenhuma mudança ocorreu sem resistências. Logo, o contexto anterior e posterior à Constituição foi marcado por intensas lutas e pela intervenção de diferentes forças políticas, como o Movimento Sem Terra (MST), o Diretas Já, a criação de organizações como a Central Única dos Trabalha- 
dores (CUT) e o Partido dos Trabalhadores (PT), entre outras ações vinculadas a movimentos sociais, preocupadas em conquistar o direito à participação e a construção democrática do Brasil (Maranhão \& Teixeira, 2006).

A transição dos anos 1980 para os anos 1990 foi um período de grande atuação dessas forças, o que posteriormente impactou a estrutura social do País e a institucionalidade do Estado. Devido a tal fato, o período passou a ser considerado um marco na história do Brasil e despertou o interesse dos pesquisadores, que buscavam compreender a dinâmica na qual se deu a redemocratização do País.

Nesse período, o foco dos estudos consistia em analisar o papel dos movimentos sociais nesse processo, bem como sua posterior inserção na estrutura institucional do Estado. No entanto, após a promulgação da Constituição, os estudos sobre os movimentos sociais ganharam outro enfoque e começaram a surgir diferentes abordagens sobre a temática participação social.

Conforme relata Tatagiba (2011), os estudos sobre movimentos sociais, tão em voga na década de 1980, deixam de ser o foco de estudo para darem lugar à literatura sobre a participação da sociedade civil nos espaços públicos, emergente desde então. Segundo a autora, a agenda de pesquisa, além de crescente, apresenta uma combinação interessante entre as abordagens quantitativas e qualitativas, fomentando diferentes olhares sobre os fatos.

Destacados os aspectos relevantes, estabelece-se como objetivo deste trabalho anali- sar a produção científica sobre a participação social após a promulgação da CF/88, a fim de compreender como essa temática tem sido estudada. Após 28 anos da promulgação da Constituição, que abriu oportunidades de diálogo entre Estado e sociedade civil, é importante analisar o que se pesquisou sobre a temática, quem tem se dedicado a estudar o tema, em quais instituições e em quais áreas a participação vem sendo discutida, entre outras questões a que este metaestudo busca responder.

Logo, objetiva-se, a partir deste trabalho, contribuir com a agenda de pesquisa sobre a participação social, além de apontar como se dá o debate atual na área e em quais âmbitos está sendo discutida, o que nos permitirá verificar as transformações sofridas ao longo do tempo e o que ainda continua sendo foco de discussão entre os pesquisadores.

Para atingir tal objetivo, estruturou-se o artigo da seguinte forma: além desta parte introdutória, realizou-se uma revisão da literatura sobre a participação. Logo após foram expostos os procedimentos metodológicos adotados juntamente com os resultados e as discussões sobre eles, e por fim, foram descritas as considerações finais do trabaIho.

\section{REFERENCIAL CONCEITUAL E ARGU- MENTATIVO}

Participação social: Alguns apontamentos

A ampliação da participação social nas decisões governamentais emergiu como demanda da sociedade civil, tendo em vista o contexto anterior à Constituição, marcado 
por graves problemas sociais, crise no setor público, autoritarismo da Administração Pública e a mobilização da população (Tatagiba, 2009).

Como consequência, a disseminação das instituições participativas fez parte da estratégia de criação de um sistema descentralizado e participativo promovido pelos novos sujeitos políticos, sobretudo na década de 1980. Esses novos sujeitos, os quais integravam os movimentos negro, de mulheres, socioambientalista, indígena, homossexual, de pessoas com deficiência, de crianças e adolescentes, sem-terra, sem-teto, trabaIhadores, entre outros, atuaram de maneira decisiva na construção de um projeto participativo que possibilitaria ser um instrumento de democratização e publicização do Estado (Moroni, 2006).

Segundo Milani (2008), "participação" é um conceito demasiadamente amplo, podendo ser participação popular, cidadã, democrática, institucional (Quadro 1), entre outras denominações usadas para referir-se à inclusão dos cidadãos no processo decisório das políticas públicas. Corroborando, Lavalle (2011) afirma que a multidimensionalidade dos sentidos práticos, teóricos e institucionais torna a participação um conceito esquivo e as tentativas de definir seus efeitos, "escorregadias".

Milani (2008) aponta serem múltiplas as origens do discurso sobre a participação, incluindo desde agências internacionais de cooperação para o desenvolvimento, como Banco Mundial, Organização de Cooperação e de Desenvolvimento Econômico (OCDE), em prol dos programas de reforma e descentralização do Estado, passando pela reivindicação de alguns governos locais visando um projeto de participação dos cidadãos, até o reclame dos movimentos sociais por sua propagação. Para o autor, a participação deriva de uma concepção de cidadania ativa, ou seja, envolve relações entre as pessoas que atuam ativamente na comunidade política e aquelas que não se envolvem, gerando, assim, situações de conflito e manifestações de interesses. Assim como Milani (2008), Villela, Vidal e Ferraz (2014) entendem a participação como um conjunto de múltiplas ações que atores sociais desenvolvem para influenciar a formulação, execução, fiscalização e avaliação das políticas públicas.

Dessa forma, Lavalle (2011) aponta que o ideário de participação entra no cenário nacional como uma categoria prática, a fim de conferir sentido à ação coletiva de atores populares. Para o autor, a participação emerge nos anos 1960 carregada de uma visão emancipatória das camadas populares. Nessa fase, a participação era definida como popular, e participar significava apostar na agência das camadas populares e tornar o povo ator da sua própria história. Dessa forma, a participação aparece como uma resposta contra a injustiça social e, até mesmo, como um recurso capaz de fazer avançar a pauta de demandas distributivas, de acesso a serviços públicos e de efetivação de direitos das camadas populares.

Após essa fase, o ideário participativo adquiriu novo perfil, e a participação, que antes era popular, tornou-se cidadã. Segundo Lavalle (2011), a liberalização política e as mobilizações pela democracia criaram um ambiente em que a participação popular absorveu também conteúdo liberal democráti- 
co. Assim, o ideário participativo herdado da fase anterior tornou-se inadequado, pois a participação passou a ser vista como além de um compromisso com os segmentos populares. Dessa forma, os atores engajados com a participação passaram a reelaborar seu discurso em termos de participação cidadã, e, de acordo com Lavalle (2011), o campo dos atores sociais diversificou-se com a multiplicação das organizações não governamentais (ONGs). Assim, o ideário participativo adquiriu aparências mais abstratas e foi consagrado, em 1988, como direito do cidadão para além da participação eleitoral (Lavalle, 2011).

Como categoria da teoria democrática, a participação foi utilizada principalmente em teorizações orientadas para a crítica interna da democracia, isto é, desempenhou papel importante no desenvolvimento de modelos de democracia que objetivavam criticar as compreensões minimalistas sem abandonar a defesa da própria democracia (Lavalle, 2011).

No Brasil, a participação foi acompanhada pela institucionalização de vários espaços dentro da estrutura estatal, nos quais buscava o diálogo entre o Estado e a sociedade, classificada, assim, como participação institucional (Abers, Serafim, \& Tatagiba, 2011). Entre os espaços criados, destacam-se os orçamentos participativos, as consultas públicas e, principalmente, os conselhos gestores de políticas públicas e as conferências, devido ao fato de ser condicionado o repasse de recursos federais à existência e funcionamento destes.

Quadro 1. Multidimensionalidade do conceito de participação

\begin{tabular}{|l|l|l|}
\hline PARTICIPAÇÃO & \multicolumn{1}{|c|}{$\begin{array}{c}\text { PRINCIPAIS MOVIMEN- } \\
\text { TOS/INSTITUIÇÕES } \\
\text { ENVOLVIDOS(AS) }\end{array}$} & \multicolumn{1}{|c|}{ VISÃO SOBRE A PARTICIPAÇÃO } \\
\hline Popular & Movimentos sociais & $\begin{array}{l}\text { Emancipatória (emancipação das camadas po- } \\
\text { pulares) }\end{array}$ \\
\hline Cidadã & ONGs & Abstrata \\
\hline Democrática & Instituições participativas* & Crítica (contra a própria democracia) \\
\hline Institucional & Instituições participativas & Dialógica (entre o Estado e a sociedade civil) \\
\hline
\end{tabular}

Todo esse aparato institucionalizado evidencia que o projeto participativo se impôs como princípio na sociedade brasileira e passou a apresentar importante representatividade na estrutura estatal (Almeida \& Tatagiba, 2012; Lüchmann, 2007). No entanto, ainda hoje, muitos são os desafios que colocam em risco uma participação mais efetiva e de qualidade.
Maranhão e Teixeira (2006) apontam quatro desafios para a participação: 1) a articulação entre participação e modelos de desenvolvimento; 2) a busca pela eficácia e efetividade dos canais de participação onde os atores possam exercer sua representação; 3) a percepção entre os atores dos diferentes discursos envolvidos no processo de diálogo; 4) a articulação entre os espaços participativos, contribuindo para que se reforcem 
e contribuam para o empoderamento social e a boa gestão pública.

Por fim, é válido ressaltar que, embora os autores reconheçam os vários desafios para uma participação mais efetiva, eles também afirmam que é somente por meio da participação política que os cidadãos alcançam a sua autonomia, um fator determinante para a emancipação social (Hamel, 2009).

\section{PROCEDIMENTOS METODOLÓGICOS}

\section{Características da pesquisa}

De modo a analisar o que tem sido pesquisado a respeito da temática participação social após a promulgação da $\mathrm{CF} / 88$, realizou-se um estudo de abordagem qualitativa, que, segundo Denzin e Lincoln (2006), compreende um conjunto de procedimentos materiais e interpretativos que possibilitam analisar o que os fatos representam em seus cenários naturais e o significado que as pessoas Ihes conferem. $O$ estudo classificou-se, ainda, como descritivo, por ter o objetivo de montar um quadro analítico sobre a produção científica que abrange o tema aqui pesquisado.

Entendendo que é o problema que leva à definição do método (Rocha, 2005), para atingir o objetivo proposto, fez-se a opção por realizar um metaestudo. De acordo com Castro (2001), o metaestudo consiste numa revisão planejada para responder a uma pergunta específica e que utiliza métodos explícitos e sistemáticos para identificar, selecionar e avaliar criticamente os estudos incluídos na revisão. Para Wood e Chueke (2008), esse tipo de estudo é relevante, pois possibilita à comunidade acadêmica conhecer o que está sendo produzido sobre determinado tema.

\section{Operacionalização da pesquisa}

A operacionalização do metaestudo baseia-se na sistematização de um conjunto de dados obtidos a partir da literatura pesquisada. Inicia-se com a escolha do tema e da literatura a ser analisada; após, faz-se o levantamento das informações descritas no material bibliográfico, e finaliza-se com a análise e a apresentação dos resultados (Brito \& Berardi, 2010; Cooper \& Lindsay, 1998).

Dessa forma, a aplicação do método foi realizada buscando artigos científicos que continham no título o descritor "participação social" ou "participação" em bancos de dados das bibliotecas eletrônicas Scientific Electronic Library Online (SciELO) e na Scientific Periodicals Electronic Library (SPELL) e Comissão de Aperfeiçoamento de Pessoal do Nível Superior (CAPES).

È importante destacar que as bases ScIELO, SPELL e CAPES foram utilizadas considerando-se a relevância que apresentam para a academia brasileira. Nessas bases, utilizando critérios de consulta como autor, assunto ou palavra chave, é possível ter acesso à produção acadêmica atual e de qualidade. Outro fator importante foi o tamanho e o alcance do acervo dessas plataformas. Os periódicos CAPES oferecem facilidade de acesso a informações científicas nacionais e internacionais. A SclELO conta com 1.221 periódicos vinculados à sua base de dados $e$ um montante de 523.810 artigos, e a SPELL conta com artigos desde a década de 1960. Por esses fatos e pela abrangência dessas bases, elas foram escolhidas para subsidiar 


\section{A PARTICIPAÇÃO SOCIAL PÓS-CONSTITUIÇÃO DE 1988: 0 QUE SE TEM DISCUTIDO A RESPEITO?}

a composição do artigo.

A técnica de análise utilizada foi a de conteúdo, que Bardin (2011) define como "um conjunto de técnicas de análise das comunicações que utiliza procedimentos sistemáticos e objetivos de descrição do conteúdo das mensagens" (p. 44). Ainda segundo Bardin (2011), a análise de conteúdo compreende três etapas principais, sendo elas: a pré-análise, a exploração do material e o tratamento dos resultados, inferência e interpretação.

Nesse estudo, a pré-análise correspondeu à fase de identificação e de recolhimento de todo os artigos encontrados. Nesse sentido, utilizando o descritor "participação social" e "participação", foi encontrado um total de 120 publicações. A seleção dos textos tinha o intuito de abranger os principais momentos da trajetória da participação social após a promulgação da CF/88, dessa forma os artigos procurados estavam dentro do universo temporal de 1988 até 2014.

Após essa primeira etapa, realizou-se a exploração do material, onde analisaram-se os textos, para validar o ajustamento ao assunto e também como forma de subsidiar a realização das análises. Após o descarte dos artigos duplicados, a leitura pormenorizada de seus resumos e a aplicação do critério de inclusão (artigos cujo tema central era participação social), permaneceram 70 artigos, os quais foram lidos na íntegra. É válido destacar que todo o procedimento de busca ocorreu por meio da avaliação por pares, o que significa que dois autores realizaram ao mesmo tempo a busca nas bases de dados empregando o mesmo descritor. Em seguida, para a exclusão dos artigos, ambos leram o mesmo resumo, e a exclusão foi feita de comum acordo.

Após essas etapas, conduziu-se o tratamento dos resultados por meio de técnicas de categorização e quantificação. Ressalta-se que a trajetória analítica adotada teve como base os estudos de Rodrigues e Moreira (2016) e Lage e Emmendoerfer (2010). A investigação teve como elemento norteador as seguintes categorias analíticas: i) o período de publicação, ii) o perfil da publicação, iii) a temática e iv) o perfil metodológico. No que se refere ao período analisado, buscou-se identificar os anos em que foram publicados os artigos, dando ênfase ao período dos governos, devido à relação entre os governos e a participação social.

No perfil da publicação, atentou-se em identificar os autores, bem como as instituições das quais fazem parte, além do periódico em que o artigo foi publicado.

Na categoria temática, buscou-se averiguar quais os principais temas discutidos nos artigos e as áreas pesquisadas.

Por fim, para análise do perfil metodológico, verificou-se a classificação adotada pelo artigo (teórico, empírico ou teórico-empiríco), a abordagem (qualitativa, quantitativa ou mista) e as técnicas de coleta de dados.

Dessa forma, com a metodologia adotada, foi possível inferir o campo de estudo sobre participação social nos últimos anos no Brasil, sendo os resultados apresentados no próximo tópico.

\section{RESULTADOS E DISCUSSÕES}

\section{Período de publicações}


Dentro do marco temporal estabelecido para análise deste estudo, a proposta foi verificar a produção científica que trata do tema participação social após a promulgação da CF/88. No entanto, evidências empíricas indicam que a orientação política influencia uma maior ou menor participação da sociedade civil na gestão pública. A partir dessa informação, além do período temporal anteriormente estabelecido (1988-2014), achou-se apropriado analisar os trabalhos de acordo com o período de governo, conforme disposto na Tabela 1.

Tabela 1. Número de artigos publicados por ano e por período de governo

\begin{tabular}{|c|c|c|c|c|}
\hline Ano & Frequência & Período & Governo & Percentual \\
\hline 1992 & 1 & 1990-1992 & Fernando Collor de Melo & $1,43 \%$ \\
\hline 1994 & 1 & 1993-1994 & Itamar Franco & $1,43 \%$ \\
\hline 1996 & 1 & \multirow{4}{*}{$\begin{array}{l}1995-1998 \\
1999-2002\end{array}$} & \multirow{4}{*}{$\begin{array}{l}\text { Fernando Henrique Cardoso } \\
\text { Fernando Henrique Cardoso }\end{array}$} & \multirow[t]{2}{*}{$1,43 \%$} \\
\hline 2001 & 1 & & & \\
\hline 2002 & 2 & & & $4,29 \%$ \\
\hline 2003 & 2 & & & \multirow{5}{*}{$11,43 \%$} \\
\hline 2004 & 1 & \multirow{4}{*}{ 2003-2006 } & \multirow{4}{*}{ Luís Inácio Lula da Silva } & \\
\hline 2005 & 3 & & & \\
\hline 2006 & 2 & & & \\
\hline 2007 & 3 & & & \\
\hline 2008 & 6 & \multirow{6}{*}{$2007-2010$} & \multirow{6}{*}{ Luís Inácio Lula da Silva } & \multirow{6}{*}{$38,57 \%$} \\
\hline 2009 & 8 & & & \\
\hline 2010 & 10 & & & \\
\hline 2011 & 8 & & & \\
\hline 2012 & 10 & & & \\
\hline 2013 & 8 & & & \\
\hline & & \multirow[t]{2}{*}{$2011-2014$} & & \multirow[t]{2}{*}{$41,43 \%$} \\
\hline 2014 & 3 & & Dilma Rousseff & \\
\hline Total & 70 & & & $100,00 \%$ \\
\hline
\end{tabular}

A partir dos dados apresentados, verificou-se que o primeiro artigo a abordar a temática "participação social" foi publicado no ano de 1992, na Revista Saúde e Sociedade, tendo como título "Movimento social e participação: A saúde na esfera pública".

Nos anos iniciais, de 1992 a 2002, a publi- cação sobre o tema era baixa, com média de 1,2 artigo por ano. Nota-se, no entanto, a concentração dos estudos no período pós2003, com destaque a partir do ano de 2010.

Os resultados corroboram as evidências empíricas, que indicam uma relação entre a orientação do governo e uma maior ou me- 


\section{A PARTICIPAÇÃO SOCIAL PÓS-CONSTITUIÇÃO DE 1988: 0 QUE SE TEM DISCUTIDO A RESPEITO?}

nor participação. Conforme relata Avritzer (2012), desde a chegada do PT ao Governo Federal, em 2003, houve uma ampliação dos mecanismos participativos. Teixeira, Souza e Lima (2012), corroborando esse relato, apontam que, dos 59 conselhos vinculados a órgãos do Governo Federal, 25 foram criados ao longo do governo petista. Tal fato refletiu nas produções acadêmicas, pois, como exposto, houve um aumento considerável de estudos que abordaram a participação social após o início dos governos Lula e Dilma.

\section{Perfil da publicação}

A primeira dimensão observada para descrever o perfil da publicação foram os periódicos em que foram publicados os trabalhos. $\mathrm{Na}$ Tabela 2, é possível verificar que a $R e-$ vista Ciência \& Saúde Coletiva é a que mais possui artigos publicados sobre a temática "participação social", seguida da Revista Saúde e Sociedade.
É interessante notar que há uma predominância dos periódicos da área da saúde que tratam da participação social. Tal fato pode estar ligado ao pioneirismo dessa área no controle social. A legislação brasileira institucionalizou a prática participativa com a Lei n. 8.142, que dispõe sobre a participação da comunidade na gestão do Sistema Único de Saúde e sobre as transferências intergovernamentais de recursos financeiros, bem como institui as instâncias colegiadas de participação, conferências e conselhos de saúde, atribuindo-lhes papéis deliberativos e fiscalizadores. De acordo com Teixeira, Vianna, Cavalcanti, e Cabral (2009), o cumprimento desses papéis passou a ser fortemente examinado por pesquisadores da área de saúde coletiva que buscavam avaliar principalmente a efetividade das instâncias participativas.

Além dos periódicos da área da saúde, nota-se também uma concentração de publicações em periódicos da área de Administração Pública.

Tabela 2. Periódicos com maior número de publicações

\begin{tabular}{|c|c|c|}
\hline Periódicos & Frequência & Percentual \\
\hline Ciência \& Saúde Coletiva & 11 & $16 \%$ \\
\hline Saúde e Sociedade & 6 & $9 \%$ \\
\hline Revista Administração Pública (RAP) & 5 & $7 \%$ \\
\hline Physis Revista de Saúde Coletiva & 4 & $6 \%$ \\
\hline Administração Pública e Gestão Social (APGS) & 3 & $4 \%$ \\
\hline Cadernos EBAPE.BR & 3 & $4 \%$ \\
\hline Cadernos Gestão Pública e Cidadania & 2 & $3 \%$ \\
\hline Eccos Revista Cientifica & 2 & $3 \%$ \\
\hline Emancipação & 2 & $3 \%$ \\
\hline Revista Katálysis & 2 & $3 \%$ \\
\hline Saúde em Debate & 2 & $3 \%$ \\
\hline Outros* & 28 & $40 \%$ \\
\hline Total & 70 & $100 \%$ \\
\hline
\end{tabular}

* Representam os periódicos que obtiveram frequência única de participação na distribuição de artigos analisados. 
Ainda tratando sobre o perfil da publicação, outro elemento analisado diz respeito aos autores dos estudos. A Tabela 3 destaca o protagonismo das autoras Rosângela Minardi Mitre Cotta e Poliana Cardoso Martins nas publicações.

É válido ressaltar que os sete primeiros pesquisadores apresentados na Tabela 3 são vinculados à Universidade Federal de Viço- sa (UFV); isso nos permitiu identificar uma parceria entre eles, já que atuaram em conjunto na maioria dos artigos analisados.

Foi possível identificar, também, uma parceria entre os pesquisadores do Consorci Hospitalari de Catalunya, em Barcelona, Espanha, e Institute for Health Sector Development, em Londres, com uma frequência de dois artigos por autor.

Tabela 3. Principais autores

\begin{tabular}{lcc}
\hline \multicolumn{1}{c}{ Autor } & $\begin{array}{c}\text { Frequên- } \\
\text { cia }\end{array}$ & $\begin{array}{c}\text { Porcenta- } \\
\text { gem }\end{array}$ \\
\hline Rosângela Minardi Mitre Cotta & 4 & $2,21 \%$ \\
Poliana Cardoso Martins & 3 & $1,66 \%$ \\
Fábio Farias Mendes & 2 & $1,10 \%$ \\
Mariana de Melo Cazal & 2 & $1,10 \%$ \\
Rodrigo Siqueira Batista & 2 & $1,10 \%$ \\
Silvia Eloiza Priore & 2 & $1,10 \%$ \\
Sylvia do Carmo Castro Franceschinni & 2 & $1,10 \%$ \\
Alcides da Silva Diniz & 2 & $1,10 \%$ \\
Ana Paula Campos Pereira & 2 & $1,10 \%$ \\
Eliane Siqueira Campos Gonzalez & 2 & $1,10 \%$ \\
Francini Lube Guizardi & 2 & $1,10 \%$ \\
Ida Cristina Leite Veras & 2 & $1,10 \%$ \\
Ilma Kruze Grande de Arruda & 2 & $1,10 \%$ \\
Maria Rejane Ferreira da Silva & 2 & $1,10 \%$ \\
Verônica Morais Ximenes & 2 & $1,10 \%$ \\
Demais autores* & 148 & $81,77 \%$ \\
\hline Total & 181 & $100,00 \%$ \\
\hline
\end{tabular}

* Representam os pesquisadores que obtiveram frequência única de participação na distribuição de artigos analisados.

Os resultados obtidos na Tabela 3 reforçam as informações trazidas pela dimensão instituição, na Tabela 4. A UFV foi a instituição que registrou maior número de autores filiados, juntamente com a Universidade de Brasília (UnB).

Entre os cinco artigos encontrados com ori- gem na UFV, quatro deles referem-se ao estudo dos conselhos de saúde e um sobre o conselho de turismo. Já na UnB, a temática mais tratada está vinculada à gestão ambiental, concentrando três dos cinco artigos analisados. 
Rio de Janeiro (UERJ), Universidade Federal da Bahia e Universidade Federal de Minas Gerais, a concentração temática deu-se sobre a gestão ambiental, com três trabalhos, sendo dois deles da UERJ, e a área da saúde, com três trabalhos, um em cada instituição.

Tabela 4. Número de artigos por instituição do primeiro autor

\begin{tabular}{|c|c|c|}
\hline Instituição do $1^{\circ}$ autor & Frequência & Percentual \\
\hline Universidade Federal de Viçosa (UFV) & 5 & $7 \%$ \\
\hline Universidade de Brasília (UnB) & 5 & $7 \%$ \\
\hline Universidade do Estado do Rio de Janeiro (UERJ) & 4 & $6 \%$ \\
\hline Universidade Federal da Bahia (UFBA) & 4 & $6 \%$ \\
\hline Universidade Federal de Minas Gerais (UFMG) & 4 & $6 \%$ \\
\hline Universidade Federal do Rio Grande do Sul (UFRGS) & 3 & $4 \%$ \\
\hline Consorci Hospitalari de Catalunya & 2 & $3 \%$ \\
\hline Instituto Federal do Espírito Santo (IFES) & 2 & $3 \%$ \\
\hline Universidade Federal de Pernambuco (UFPE) & 2 & $3 \%$ \\
\hline Universidade Federal do Piauí (UFPI) & 2 & $3 \%$ \\
\hline Universidade de São Paulo (USP) & 2 & $3 \%$ \\
\hline Demais instituições* & 35 & $50 \%$ \\
\hline Total & 70 & $100 \%$ \\
\hline
\end{tabular}

* Representam as instituições que obtiveram frequência única de participação na distribuição de artigos analisados.

\section{Temática}

$\mathrm{Na}$ categoria temática, buscou-se verificar quais os direcionamentos dados à produção científica envolvendo a participação social.

Tabela 5. Número de artigos por área de estudo

\begin{tabular}{|l|c|c|}
\hline \multicolumn{1}{|c|}{ Temática } & Frequência & $\begin{array}{c}\text { Percen- } \\
\text { tual }\end{array}$ \\
\hline Políticas públicas & 30 & $42,86 \%$ \\
\hline Arranjos participativos & 18 & $25,71 \%$ \\
\hline Gestão ambiental & 11 & $15,71 \%$ \\
\hline Políticas sociais & 5 & $7,14 \%$ \\
\hline Associativismo & 4 & $5,71 \%$ \\
\hline Movimentos sociais & 2 & $2,86 \%$ \\
\hline Total & $\mathbf{7 0}$ & $\mathbf{1 0 0 , 0 0 \%}$ \\
\hline
\end{tabular}

Nessa perspectiva, com base na Tabela 5, foi possível elencar seis principais temáticas: políticas públicas, arranjos participativos, gestão ambiental, políticas sociais, associativismo e movimentos sociais. 
Conforme evidenciado na Tabela 5 destacam-se os estudos relativos aos arranjos participativos e às políticas públicas. Sobre os arranjos participativos, entre os 18 artigos encontrados, 13 são sobre conselhos e, destes, sete referem-se aos conselhos de saúde. Como verificado no referencial teórico, a participação foi acompanhada pela institucionalização de vários espaços dentro da estrutura estatal; tal fato refletiu nas temáticas dos estudos, que passaram a abordar essa participação institucional.

Entre os trabalhos que tratam sobre políticas públicas (30 deles), 18 são voltados especificamente para o estudo da área da saúde. As demais políticas públicas estudadas são as de habitação, de turismo, saneamento e educação.

A constatação de que a área mais pesquisada é a da saúde corrobora o resultado da Tabela 3, a qual demonstra o protagonismo dos periódicos da área em realizar publicações sobre participação.

Com relação aos estudos sobre a gestão ambiental, os artigos tratam da análise dos recursos hídricos, recursos sólidos e a gestão ambiental em si. Os demais se concentraram entre as áreas das políticas sociais, do associativismo e dos movimentos sociais. Além da temática, analisou-se, por meio dos objetivos dos artigos, quais abordagens foram dadas à participação no horizonte temporal estudado. Os dados mostram que a participação social é tratada de diversas formas nos artigos investigados. Identificou-se, por meio dos três artigos publicados no período - Adorno (1992), Vilaça, (1994) e Silva e D’Arc (1996) - que, nos anos 1990, há uma preocupação com a articulação local dos atores sociais e com as potencialidades e limites dos processos participativos, tendo em vista a descentralização e democratização das atividades políticas e administrativas do Estado.

O primeiro artigo, publicado no ano de 1992, tendo como autor Rubens de C. F. Adorno, aponta essa preocupação ao propor-se delimitar teoricamente a origem e diferença entre os termos "movimentos sociais" e "participação", relacionando à teoria democrática. Nota-se que o foco dos estudos acompanha a transição do que seria a participação, anteriormente vista como emancipatória das camadas populares por meio dos movimentos sociais e, posteriormente, como direito do cidadão para além da participação eleitoral. Esse fato corrobora Tatagiba (2011), que aponta que, ao fim da década de 1980, há a transição de uma literatura focada no estudo dos movimentos sociais para a inserção da nomenclatura da participação.

A partir do ano de 2000, os estudos focaram a reflexão e aprofundamento das dimensões da participação, buscando entender como os atores sociais se envolvem nos mecanismos de participação e as tendências na relação sociedade/Estado. Destaque também para os trabalhos cujo foco de análise voltou-se para os conselhos gestores de políticas públicas. Por fim, de 2010 em diante, as temáticas mais abordadas relacionaram-se aos conselhos e à institucionalização dos arranjos participativos.

\section{Perfil metodológico}

A última categoria analisada refere-se ao perfil metodológico adotado pelos pesquisadores. Essa categoria buscou delinear os aspectos da tipologia, da abordagem e das técnicas de coletas de dados. 


\section{A PARTICIPAÇÃO SOCIAL PÓS-CONSTITUIÇÃO DE 1988: 0 QUE SE TEM DISCUTIDO A RESPEITO?}

A Tabela 6 evidencia que, em relação à tipologia, a mais adotada nos artigos foi a do tipo teórico-empírico, o que reforça o caráter prático da temática participação. Quanto à abordagem, é evidenciado o predomínio de estudos qualitativos e poucas pesquisas puramente quantitativas; na maioria das vezes, essa abordagem é utilizada juntamente com a abordagem qualitativa.

Por último, foi analisada qual a estratégia de pesquisa utilizada para a coleta dos dados. Os resultados mostraram que as técnicas mais comuns para a coleta de dados secundários foram a pesquisa bibliográfica e a análise documental, que, juntas, somaram $45,84 \%$ de frequência. A pesquisa documental tem como principal fonte de consulta legislações e normativos que institucionalizam as atividades referentes à participação social na gestão pública, além de regimentos internos e atas das reuniões dos espaços de participação, como conselhos e conferências.

As técnicas de coleta de dados primários mais utilizadas foram as entrevistas, a observação, tanto participante como não participante, e os questionários e surveys. Foi possível observar que há uma associação ente $a$ análise documental e os métodos primários de coletas de dados. Tais características são comuns aos estudos teórico-empíricos, uma vez que, na lógica da pesquisa, primeiramente constrói-se um referencial analítico e depois busca-se analisá-lo diante da realidade pesquisada.

Tabela 6. Perfil metodológico

\begin{tabular}{c|c|c|c}
\hline Perfil metodológico & Elementos & Frequência & Percentual \\
\hline \multirow{3}{*}{ TIPOLOGIA } & Teórico & 27 & $38,57 \%$ \\
& Empírico & 0 & $0,00 \%$ \\
& Teórico-empírico & 43 & $61,43 \%$ \\
& Total & 70 & $\mathbf{1 0 0 , 0 0 \%}$ \\
\hline \multirow{4}{*}{ ABORDAGEM } & Qualitativa & 58 & $83 \%$ \\
& Quantitativa & 5 & $7 \%$ \\
& Quali-quanti & 7 & $10 \%$ \\
& Total & $\mathbf{1 0 0} \%$ \\
\hline \multirow{3}{*}{ TÉCNICA DE COLETA DE DADOS } & \multicolumn{3}{c}{} \\
& Pesquisa bibliográfica & 22 & $30,56 \%$ \\
& Entrevista & 18 & $25,00 \%$ \\
& Análise documental & 11 & $15,28 \%$ \\
& Observação participante & 5 & $6,94 \%$ \\
& Observação não participante & 4 & $5,56 \%$ \\
& Questionário & 2 & $2,78 \%$ \\
& Survey & 2 & $2,78 \%$ \\
& Demais técnicas & 8 & $11,11 \%$ \\
\hline & Total & $\mathbf{7 2}$ & $\mathbf{1 0 0 , 0 0 \%}$ \\
\hline
\end{tabular}

* Representam as técnicas que obtiveram frequência única de participação na distribuição de artigos analisados. 


\section{CONSIDERAÇÕES FINAIS}

Por meio da análise da produção científica sobre a "participação social", buscou-se verificar como a temática vem sendo discutida ao longo dos anos, quem são os principais autores que discutem o tema, a quais instituições eles pertencem e qual o perfil metodológico adotado pelos trabalhos.

Diante dos resultados, é possível inferir que, após a institucionalização da participação na CF/88, os estudos acompanharam a transição sofrida pelo próprio sentido dado à participação e ampliaram a visão analítica com relação ao tema quando aumentaram os números das publicações.

Entre as publicações, observou-se que há uma concentração de trabalhos que tratam da participação na saúde, o que pode estar relacionado ao pioneirismo dessa área no controle social e pelo fato de possuir arranjos participativos mais consolidados.

Também foi perceptível o predomínio dos pesquisadores pertencentes principalmente à UFV e à UnB, sendo identificada, na primeira instituição, uma cooperação na produção científica, visto que, na maioria dos artigos analisados, os pesquisadores mais referenciados trabalharam em conjunto.

Outro aspecto identificado foi a possibilidade de estudar a participação social sob diferentes temáticas. Os estudos configuram-se como um campo plural, e as temáticas podem abranger diversas abordagens, como: políticas públicas, arranjos participativos, gestão ambiental, políticas sociais, associativismo e movimentos sociais. Devido a essa pluralidade, constataram se perfis dis- tintos de publicação, como emprego de pesquisas teórico-empíricas com enfoques tanto quantitativos quanto qualitativos, além de diferentes técnicas de coletas de dados, sendo as mais frequentes a pesquisa bibliográfica, as entrevistas e a análise documental.

Por fim, a análise também permitiu identificar algumas lacunas teóricas que ainda não foram supridas, sendo a principal delas a indagação de qual seria o formato mais propenso a facilitar o desenvolvimento democrático da sociedade por meio da participação.

Atualmente, autores como Fung e Wright, Luchmann, Avritzer, Farias, Tatagiba, Dagnino, Abers, Serafim, entre outros, continuam a engendrar estudos com o objetivo de compreender como se dão os processos participativos e como concebê-los de modo a possibilitar o empoderamento dos atores sociais e responder às demandas da sociedade. Nota-se que o foco, hoje, recai sobre o desenho institucional, a efetividade deliberativa e participativa dos arranjos participativos, o diálogo entre representantes e representados, entre outros. Dessa forma, continuamos a perseguir $o$ ideal de efetividade da participação e da sua contribuição para o fortalecimento da democracia.

\section{REFERÊNCIAS}

Abers, R., Serafim, L., \& Tatagiba, L. (2011, Agosto). Novas relações Estado-sociedade no Governo Federal brasileiro: Repertórios de participação em um Estado heterogêneo. 35ํㅡㄹ Encontro Anual da ANPOCS, CaxambuMG.

Almeida, C., \& Tatagiba, L. (2012). Os conseIhos gestores sob o crivo da política: Balan- 


\section{A PARTICIPAÇÃO SOCIAL PÓS-CONSTITUIÇÃO DE 1988: 0 QUE SE TEM DISCUTIDO A RESPEITO?}

ços e perspectivas. Serviço Social \& Sociedade, (n 109), 68-92.

Avritzer, L. (2008), Instituições participativas e desenho institucional: Algumas considerações sobre a variação da participação no Brasil democrático. Opinião Pública, 14(1), 43-64. doi:10.1590/S010462762008000100002

Avritzer, L. (2012). Conferências nacionais: Ampliando e redefinindo os padrões de participação social no Brasil. Texto para discussão, (1739), 123-142.

Bardin, L. (2011). Análise de conteúdo. São Paulo, SP: Edições 70.

Brito, R. P., \& Berardi, P. C. (2010). Vantagem competitiva na gestão sustentável da cadeia de suprimentos: Um metaestudo. RAE - Revista de Administração de Empresas, 50(2), 155-169.

Castro, A. A. (2001). Revisão sistemática e meta-análise. Recuperado de http://metodologia.org/wp-content/uploads/2010/08/ meta1.PDF

Cooper, H. M., \& Lindsay, J. J. (1998). Research synthesis and meta-analysis. In $\mathrm{L}$. Bickman, \& D. J. Rog (Eds.), Handbook of applied social research methods (pp. 315342). Thousand Oaks, EUA: Sage Publications.

Denzin, N. K., \& Lincoln, Y. S. (2006). O planejamento da pesquisa qualitativa: Teorias e abordagens (S. R. Netz, Trad.). Porto Alegre, RS: Artmed.

Hamel, M. R. (2009). Movimentos sociais e democracia participativa. Revista Espaço Acadêmico, (95), 34-56.

Lage, M. L. C., \& Emmendoerfer, M. L. (2010). Congruências e peculiaridades da produção científica em administração sobre assédio moral nas organizações: Perspectivas para a gestão pública. IV Encontro de Administração Pública e Governança da ANPAD, Curitiba, PR.

Lavalle, A. G. (2011). Participação: Valor, utilidade, efeitos e causa. In: R. R. Pires (Org.), Efetividade das instituições participativas no Brasil: Estratégias de avaliação (pp. 3342). Brasília, DF: IPEA.

Lüchmann, L. H. H. (2007). Democracia deliberativa, pobreza e participação política. Revista Política \& Sociedade, (11), 34-55.

Maranhão, T. A., \& Teixeira, A. C. C. (2006). Participação no Brasil: Dilemas e desafios contemporâneos. In. M. C. Albuquerque (Org.), Participação popular em políticas públicas: Espaço de construção da democracia brasileira (Vol. 1, pp. 123-234). São Paulo, SP: Instituto Polis.

Martins, M.F. A distribuição do poder nos conselhos municipais de saúde: o caso dos municípios de Ubá e Viçosa- MG. Viçosa: UFV, 2010. 112f. Dissertação (Mestrado em Administração)- Programa de Pós Graduação em Administração, Universidade Federal de Viçosa, Viçosa, 2010.

Milani, C R. S. (2008). O princípio da participação social na gestão de políticas públicas locais: Uma análise de experiências latino-americanas e europeias. RAP-Revista de Administração Pública, 42(3), 551-579. 
Moroni, J. A. (2006). O direito a participação no Governo Lula. Recuperado de http://www. icsw.org/globalconferences/Brazil2006/papers/jose_antonio_moroni.pdf $>$.

Rocha, A. (2005). Métodos qualitativos em administração: Usos e abusos. [Informativo]. Associação Nacional de Pós-Graduação e Pesquisa em Administração (ANPAD).

Rodrigues, L. P. D., \& Moreira, V. S. (2016). Habitação e políticas públicas: $O$ que se tem pesquisado a respeito? Urbe: Revista Brasileira de Gestão Urbana, 8(2), 167-180. doi:10.1590/2175-3369.008.002.AO01

Silva, P. R. G., \& D’Arc, H. R. (1996). Participação social: Instrumento de gestão pública? Elementos para um debate sobre a gestão de cidades brasileiras. Quais as perspectivas nos anos 90? Revista de Administração Pública (RAP), 30(2), 44-70.

Tatagiba, L. (2009). Relação entre movimentos sociais e instituições políticas no cenário brasileiro recente: Reflexões em torno de uma agenda preliminar de pesquisa. In S. E. Alvarez, S. E. Baiocchi, G. Laó-Montes, A. J. M. Rubin, \& M. Thayer (Orgs.), Interrogating the civil society agenda: Social movements, civil society, and democratic innovation.

Tatagiba, L. (2011). A questão dos atores, seus repertórios de ação e implicações para o processo participativo. In IPEA/Prodep
(Org.), A efetividade das instituições participativas no Brasil: Perspectivas, abordagens e estratégias de avaliação.

Teixeira, A. C. C., Souza, C. H. L., \& Lima, P. P. F. (2012) Conselhos e conferências nacionais: O que são, quantos existem e para que servem. Recuperado de http://www.inesc.org. br/noticias/noticias-gerais/2012-1/novembro/ conselhos-e-conferencias-nacionais-o-que-sao-quantos-existem-e-para-que-servem

Teixeira, M. L., Vianna, W., Cavalcanti, M. L., \& Cabral, M. P. (2009). Participação em saúde: Do que estamos falando? Sociologias, 11, (21), 218-251.

Teixeira, S.M. Descentralização e Participação Social: o novo desenho das políticas sociais. Rev. Katál. Florianópolis v. 10 n. 2 p. 154-163 jul./dez. 2007.

Villela, L. E., Vidal, M. O., \& Ferraz, L. (2014, Abril). Gestão social e políticas públicas no estado do Rio de Janeiro: Uma análise a partir da percepção dos conselheiros municipais. VIII Encontro Nacional de Pesquisadores em Gestão Social, Cachoeira, BA.

Wood, T., Jr., \& Chueke, G. V. (2008). Ranking de produção científica em administração de empresas no Brasil. Revista de Administração Mackenzie, 9(4), 13-31. doi:10.1590/ S1678-69712008000400003 